\title{
Predicting arene rate coefficients with respect to hydroxyl and other free radicals in the gas-phase: a simple and effective method using a single topological descriptor
}

\author{
M. R. McGillen ${ }^{1}$, C. J. Percival ${ }^{1}$, G. Pieterse ${ }^{2}$, L. A. Watson $^{3}$, and D. E. Shallcross ${ }^{3}$ \\ ${ }^{1}$ School of Earth, Atmospheric and Environmental Sciences, The University of Manchester, The Sackville Building, Sackville \\ Street, P.O. Box 88, Manchester M60 1QD, UK \\ ${ }^{2}$ Department of Air Quality and Climate Change, Energy Research Centre for the Netherlands, P.O. Box 1, 1755 ZG Petten, \\ The Netherlands \\ ${ }^{3}$ Biogeochemistry Research Centre, School of Chemistry, The University of Bristol, Cantock's Close BS8 1TS, UK
}

Received: 13 November 2006 - Published in Atmos. Chem. Phys. Discuss.: 26 February 2007

Revised: 23 May 2007 - Accepted: 2 July 2007 - Published: 6 July 2007

\begin{abstract}
The reactivity of aromatic compounds is of great relevance to pure and applied chemical disciplines, yet existing methods for estimating gas-phase rate coefficients for their reactions with free radicals lack accuracy and universality. Here a novel approach is taken, whereby strong relationships between rate coefficients of aromatic hydrocarbons and a Randić-type topological index are investigated, optimized and developed into a method which requires no specialist software or computing power.

Measured gas-phase rate coefficients for the reaction of aromatic hydrocarbons with $\mathrm{OH}$ radicals were correlated with a calculated Randić-type index, and optimized by including a term for side chain length. Although this method is exclusively for use with hydrocarbons, it is more diverse than any single existing methodology since it incorporates alkenylbenzenes into correlations, and can be extended towards other radical species such as $\mathrm{O}\left({ }^{3} P\right)$ (and tentatively $\mathrm{NO}_{3}, \mathrm{H}$ and $\mathrm{Cl}$ ). A comparison (with species common to both techniques) is made between the topological approach advocated here and a popular approach based on electrophilic subsituent constants, where it compares favourably.

A modelling study was carried out to assess the impact of using estimated rate coefficients as opposed to measured data in an atmospheric model. The difference in model output was negligible for a range of $\mathrm{NO}_{\mathrm{x}}$ concentrations, which implies that this method has utility in complex chemical models.

Strong relationships (e.g. for $\mathrm{OH}, R^{2}=0.96$ ) between seemingly diverse compounds including benzene, multisubstituted benzenes with saturated, unsaturated, aliphatic and cyclic substitutions and the nonbenzenoid aromatic, azulene
\end{abstract}

Correspondence to: C. J. Percival

(c.percival@manchester.ac.uk) suggests that the Randić-type index presented here represents a new and effective way of describing aromatic reactivity, based on a quantitative structure-activity relationship (QSAR).

\section{Introduction}

Since its conception, the term "aromatic" used in description of a specific class of organic compound has been subjected to many refinements, and where ambiguity remains (e.g. where Hückel's rule is not obeyed or where the compound in question is of nonplanar geometry) consensus is met chiefly on the empirical grounds of the characteristic reactivity of aromatic compounds in general. The present study uses a quantitative structure-activity relationship to describe the reactivity of a subset of these compounds, the arenes, whose gasphase rate coefficients have up to now appeared to have no discernable correlation from knowledge of their constitution alone.

The reactivity of aromatic hydrocarbons with free radicals is of direct importance to a variety of chemical subdisciplines including atmospheric chemistry, chemical epidemiology and combustion processes. Motor vehicle emissions and fuel spillage are a major source of arenes in the urban environment (Calvert et al., 2002), resulting from the high proportion of arenes present in gasoline (especially in European and diesel formulations) and the close relationship between fuel composition and exhaust composition with respect to aromatics (Leppard et al., 1993, 1995). Arenes are classified as carcinogenic by the International Agency for Research on Cancer (IARC) and exposure has been linked to dermal

Published by Copernicus Publications on behalf of the European Geosciences Union. 


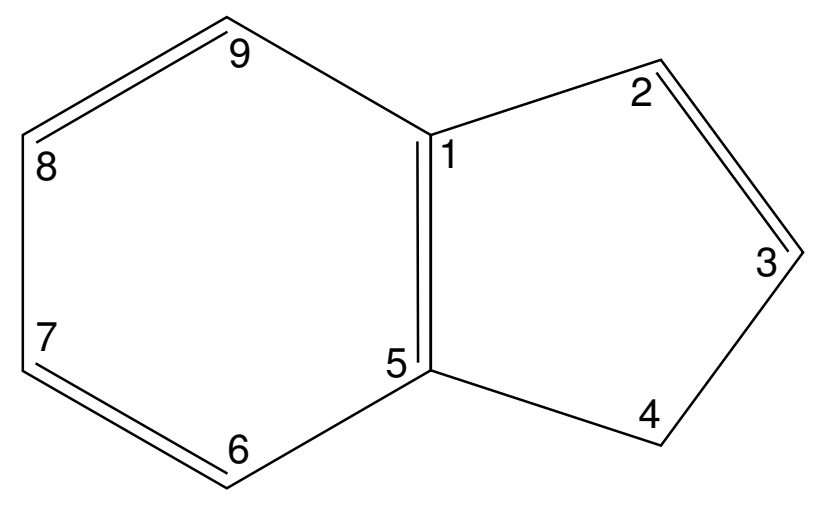

Fig. 1. Structural graph of indene.

absorption and subsequent biotransformation into harmful metabolites (Pellack-Walker and Blumer, 1986); leukaemia (Carletti and Romano, 2002), cytogenetic damage (Celik et al., 2003) and persisting neurobehavioural disturbances in humans (Mikkelsen, 1997) and laboratory rats (Gralewicz and Wiaderna, 2001).

Aromatic hydrocarbons are common trace components of the urban atmosphere, and given their associated health risk, their primacy as tropospheric ozone precursors (Derwent et al., 1996) and the contributions of their oxidation products towards secondary organic aerosol (SOA) formation (Odum et al., 1997), it is highly pertinent to investigate factors affecting the atmospheric lifetime (e.g. their reactivity towards free radicals) and the volatility of oxidation products (e.g. the branching ratio between radical addition and radical abstraction reactions) of aromatic hydrocarbons.

The present study describes an accurate and accessible method by which unknown rate coefficients can be estimated for the reaction of arenes with $\mathrm{OH}$ and $\mathrm{O}\left({ }^{3} P\right)$ radicals and provisional estimation methods for certain arene species with $\mathrm{H}$ and $\mathrm{Cl}$ (where data are sparse).

\section{Methodology}

Methods for calculating the Randić index for saturated and unsaturated hydrocarbons are described elsewhere in the literature (Randić, 1975; McGillen et al., 2006a, b). The present method is an extension of that used to calculate the Randić index for unsaturated hydrocarbons (McGillen et al., 2006b), whereby a Kekulé structure is assumed for a phenyl group. Although not a true representation of the benzene ring, the alternating single and double bond arrangement of the Kekulé structure assigns the same hydrogen-suppressed valency to each carbon atom of the aromatic ring and the valency value that is assigned is therefore unimportant, since any error associated with carbon valence is systematic and is of no concern to a correlation study such as this.
Table 1. Examples of bicyclic and monocyclic arenes belonging to $\Sigma x_{0-2}^{\circ}$.

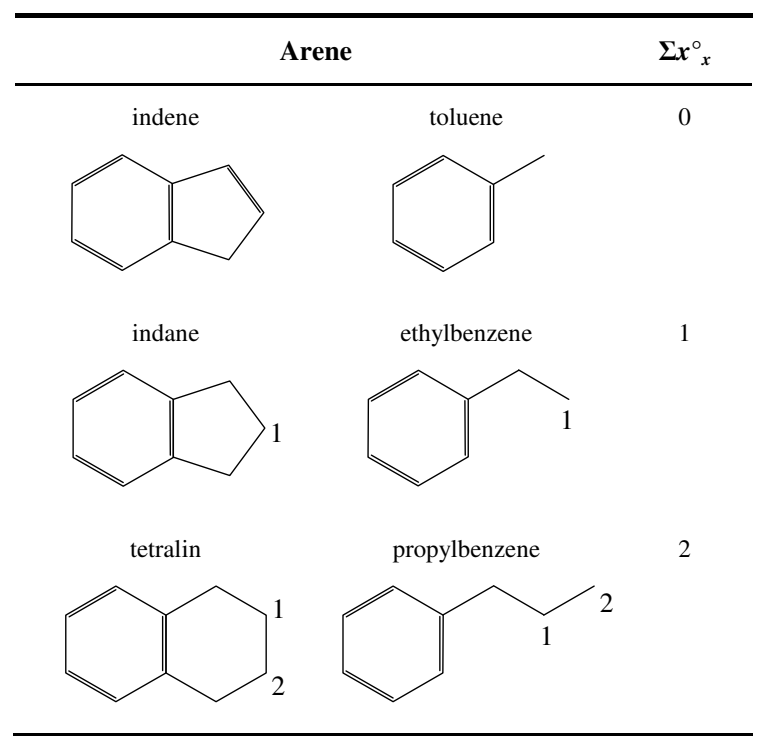

The Randić index $(R)$ is calculated using Eq. (1)

$R=\Sigma(m n)^{-0.5}$

where $m$ and $n$ are valencies of adjacent vertices joined by an edge. The following is a worked example for the structural graph of indene, (see Fig. 1).

The valencies are 4 for vertices 1 and 5, 2 for vertex 4 and 3 for vertices 2, 3, 6, 7, 8 and 9. Using Eq. (1), $R$ is calculated:

$$
\begin{aligned}
R & =(4 \times 3)^{-0.5}+(3 \times 3)^{-0.5}+(3 \times 3)^{-0.5} \\
& +(3 \times 2)^{-0.5}+(2 \times 4)^{-0.5}+(4 \times 4)^{-0.5} \\
& +(4 \times 4)^{-0.5}+(4 \times 3)^{-0.5}+(3 \times 3)^{-0.5} \\
& +(3 \times 3)^{-0.5}+(3 \times 3)^{-0.5}+(3 \times 3)^{-0.5} \\
& +(3 \times 3)^{-0.5}+(3 \times 4)^{-0.5}
\end{aligned}
$$

Where $m$ and $n$ correspond to vertices 1 and 2, 2 and 3, 2 and 3, 3 and 4, 4 and 5, 5 and 1, 5 and 1, 5 and 6, 6 and 7, 6 and 7,7 and 8,8 and 9,8 and 9 and 9 and 1 respectively, giving the result 4.46 .

One drawback of using the Kekulé structure in this approach is that certain arenes (notably those containing an ortho-substitution) will generate a slightly different index (typically \pm 0.01 ) depending on which of the two resonance structures is used in calculation of the index. Although such a minor difference is considered inconsequential for predictive purposes, for thoroughness these two values have been averaged in this study.

Similar to a phenomenon observed previously for alkenes (McGillen et al., 2006b), species plot on separate trendlines 
Table 2. Measured arene + radical room temperature rate coefficients used in this study, alongside Randić-type index and $\Sigma x_{x}^{\circ}$ subgroup for each respective arene.

\begin{tabular}{|c|c|c|c|c|c|c|c|}
\hline arene & $k_{\mathrm{OH}}$ & $k_{\mathrm{O}(3 P)}$ & $k_{\mathrm{NO}_{3}}$ & $k_{\mathrm{H}}$ & $k_{\mathrm{Cl}}$ & $R$ & $\Sigma x_{x}^{\circ}$ \\
\hline benzene & $1.25 \times 10^{-12}$ (a.) & $3.16 \times 10^{-14}$ (1.) & & $5.65 \times 10^{-14 \text { (t.) }}$ & $1.30 \times 10^{-15}(\mathrm{v})$. & 3.000 & 0 \\
\hline toluene & $5.70 \times 10^{-12}$ (b.) & $7.63 \times 10^{-14}(1)$. & $7.00 \times 10^{-17}$ (q.) & $1.35 \times 10^{-13}$ (t.) & $5.91 \times 10^{-11}(\mathrm{v})$. & 3.366 & 0 \\
\hline$p$-xylene & $1.30 \times 10^{-11}$ (c.) & $2.15 \times 10^{-13}$ & $4.97 \times 10^{-16}$ (r.) & $5.80 \times 10^{-13}$ (u.) & $1.50 \times 10^{-10(\mathrm{v} .)}$ & 3.732 & 0 \\
\hline$o$-xylene & $1.14 \times 10^{-11}$ (a.) & $1.83 \times 10^{-13(\mathrm{~m} .)}$ & $4.13 \times 10^{-16}(\mathrm{r})$. & & $1.50 \times 10^{-10}(\mathrm{v})$. & 3.741 & 0 \\
\hline$m$-xylene & $2.09 \times 10^{-11}$ (c.) & $3.98 \times 10^{-13(\mathrm{~m} .)}$ & $2.60 \times 10^{-16}$ (q.) & & $1.40 \times 10^{-10(\mathrm{v} .)}$ & 3.732 & 0 \\
\hline mesitylene & $5.75 \times 10^{-11}$ (c.) & $2.60 \times 10^{-12(n .)}$ & $8.76 \times 10^{-16}(\mathrm{r})$. & & & 4.098 & 0 \\
\hline hemimellitene & $3.27 \times 10^{-11}$ (c.) & $1.13 \times 10^{-12}(\mathrm{n})$. & $1.86 \times 10^{-15}$ (r.) & & & 4.116 & 0 \\
\hline$\psi$-cumene & $3.25 \times 10^{-11}$ (c.) & $1.02 \times 10^{-12(n .)}$ & $1.81 \times 10^{-15}(\mathrm{r})$. & & & 4.107 & 0 \\
\hline styrene & $5.86 \times 10^{-11}$ (d.) & $4.50 \times 10^{-12}$ (о.) & $1.51 \times 10^{-13}(\mathrm{~d})$. & $3.49 \times 10^{-12}(\mathrm{t})$. & $3.60 \times 10^{-10}(\mathrm{v})$. & 4.309 & 0 \\
\hline$\alpha$-methylstyrene & $5.30 \times 10^{-11}$ (e.) & & & & & 4.323 & 0 \\
\hline$\beta$-dimethylstyrene & $3.30 \times 10^{-11}$ (f.) & & & & & 4.732 & 0 \\
\hline trans-propenylbenzene & $5.99 \times 10^{-11}$ (e.) & & & & & 4.399 & 0 \\
\hline 2-propenylbenzene & & & & $4.32 \times 10^{-12}$ (t.) & & 4.444 & 0 \\
\hline indene & $7.80 \times 10^{-11}$ (g.) & & $4.10 \times 10^{-12}$ (g.) & & & 4.455 & 0 \\
\hline azulene & $2.72 \times 10^{-10}$ (h.) & & $3.90 \times 10^{-10}$ (h.) & & & 4.982 & 0 \\
\hline ethylbenzene & $6.07 \times 10^{-12}$ (a.) & $5.84 \times 10^{-14}$ & & $2.49 \times 10_{(\mathrm{t} .)}^{-13}$ & & 3.927 & 1 \\
\hline toluene, $p$-ethyl & $1.36 \times 10^{-11 \text { (i.) }}$ & & $8.58 \times 10^{-16}$ (s.) & & & 4.293 & 1 \\
\hline toluene, $o$-ethyl & $1.32 \times 10^{-11 \text { (i.) }}$ & & & & & 4.299 & 1 \\
\hline toluene, $m$-ethyl & $2.24 \times 10^{-11}$ (i.) & & & & & 4.302 & 1 \\
\hline indane & $1.91 \times 10^{-11}$ (g.) & & $7.35 \times 10^{-15}$ (g.) & & & 4.445 & 1 \\
\hline$n$-propylbenzene & $5.71 \times 10^{-12}(\mathrm{j})$. & & & & & 4.427 & 2 \\
\hline cumene & $6.61 \times 10^{-12}$ (i.) & $6.77 \times 10^{-14}(\mathrm{p})$. & & & & 4.309 & 2 \\
\hline$p$-cymene & $1.51 \times 10^{-11}(\mathrm{k})$. & & $1.00 \times 10^{-15}(\mathrm{k})$. & & & 4.675 & 2 \\
\hline tetralin & $3.44 \times 10^{-11}$ (d.) & & $8.50 \times 10^{-15}$ (q.) & & & 4.951 & 2 \\
\hline benzene, tert-butyl & $4.85 \times 10^{-12}$ (i.) & $6.64 \times 10^{-14}(\mathrm{n})$. & & & & 4.616 & 3 \\
\hline
\end{tabular}
a. Anderson et al. (2003)
b. Bohn (2001)
c. Atkinson and Aschmann (1989)
d. Atkinson and Aschmann (1988)
e. Bignozzi et al. (1981)
f. Chiorboli et al. (1983)
g. Kwok et al. (1997)
h. Atkinson et al. (1992)
i. Ohta and Ohyama (1985)
j. Atkinson (1986)
k. Corchnoy and Atkinson (1990)
1. Baulch et al. (1994)
m. Frerichs et al. (1989)
n. Cvetanovic (1987)
o. Buchta et al. (1993)
p. Frerichs et al. (1991)

q. Calvert et al. (2002)

r. Atkinson et al. (1984)

s. Bolzacchini et al. (1999)

t. Triebert et al. (1998)

u. Baulch et al. (1992)

v. Shi and Bernhard (1997) according to the total number of primary $\left(1^{\circ}\right)$, secondary $\left(2^{\circ}\right)$ and tertiary $\left(3^{\circ}\right)$ carbon atoms $\left(\Sigma x_{x}^{\circ}\right)$ present in the side chain(s), examples of these subgroups based on $\Sigma x^{\circ}$ are given in Table 1.

Correlation was improved using a nonlinear regression method to model these data, and incorporating a term for $\Sigma x^{\circ}$ using Eq. (2)

$\ln k=a_{0} \ln R+a_{1}+b_{0} \ln (D+1)$

where $R$ is the Randic index, $D$ is $\Sigma x^{\circ}$ and $a_{0}, a_{1}$ and $b_{0}$ are the model parameters, which can be determined by minimizing the $l^{2}$-norm of the difference between the rate coefficient measurements and regression model output.

\section{Results}

Table 2 lists all known measured room temperature rate coefficients for the reaction of $\mathrm{C}_{6}-\mathrm{C}_{10}$ arenes with $\mathrm{OH}, \mathrm{O}\left({ }^{3} P\right)$, $\mathrm{NO}_{3}, \mathrm{H}$ and $\mathrm{Cl}$ radicals together with the respective $\Sigma x^{\circ}$ subgroup and calculated Randić index for each species.

\subsection{OH dataset}

The $\mathrm{OH}$ dataset is the most comprehensive of those covered, and its range of reactivity extends over two orders of magnitude. Rate coefficients for a large variety of species are measured, and the dataset therefore offers the most insight into the distribution of $\Sigma x^{\circ}$ subgroups.

Figure 2 is a plot of Randić index against the logarithm of the room temperature rate coefficient $\left(\log k_{298}\right)$. When 


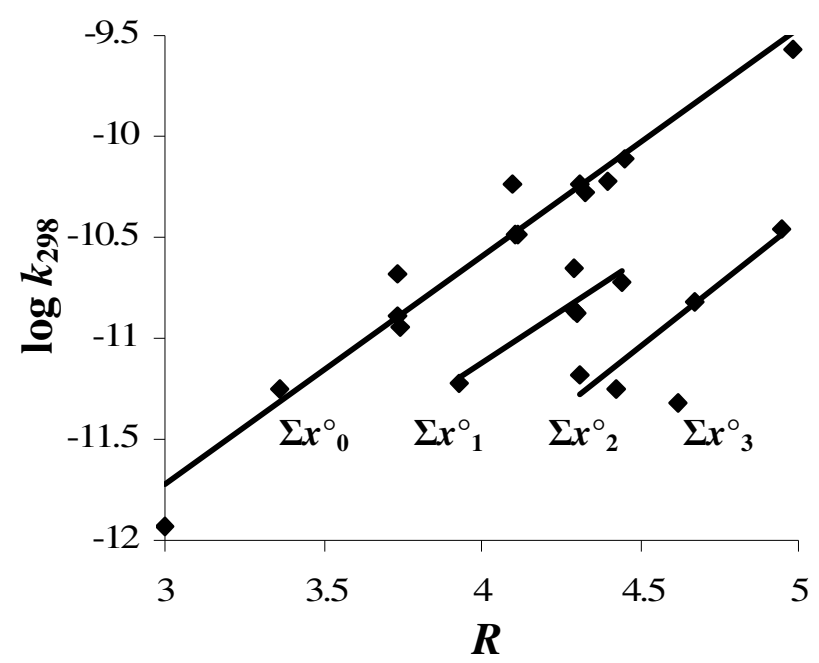

Fig. 2. A plot of Randić index against measured arene $+\mathrm{OH}$ $\log k_{298}$. Data is seen to subdivide into approximately evenly spaced, parallel subgroups, dependent on $\Sigma x_{x}^{\circ}$.

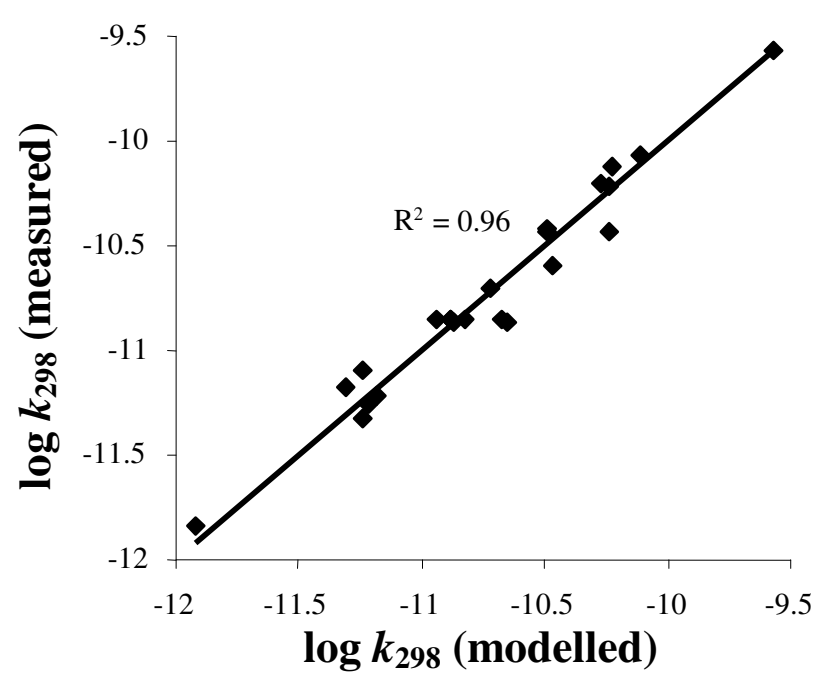

Fig. 3. $\log -\log$ plot of arene $+\mathrm{OH} k_{298}$ modelled using Eq. (2) against measured $k_{298}$.

plotted with an unmodified Randić index, data are observed to subdivide into parallel and equally offset lines, similar to correlations observed in alkene data (McGillen et al., 2006b). Scatter within respective $\Sigma x_{0-2}^{\circ}$ is minimal and the gradients of trendlines are in good agreement.

Figure 3 is a plot of $\log k_{298}$ against $\log k_{298}$ modelled using Eq. (2) where $a_{0}, b_{0}$ and $b_{1}$ are $10.21,-38.51$ and -1.11 respectively. An excellent correlation coefficient of 0.96 is observed. Species possessing $m$-substituents appear to contribute most towards the scatter, shown by the enhanced rate coefficients of $m$-xylene, mesitylene and $m$-ethyltoluene, which results from contributions to the rate coefficients from

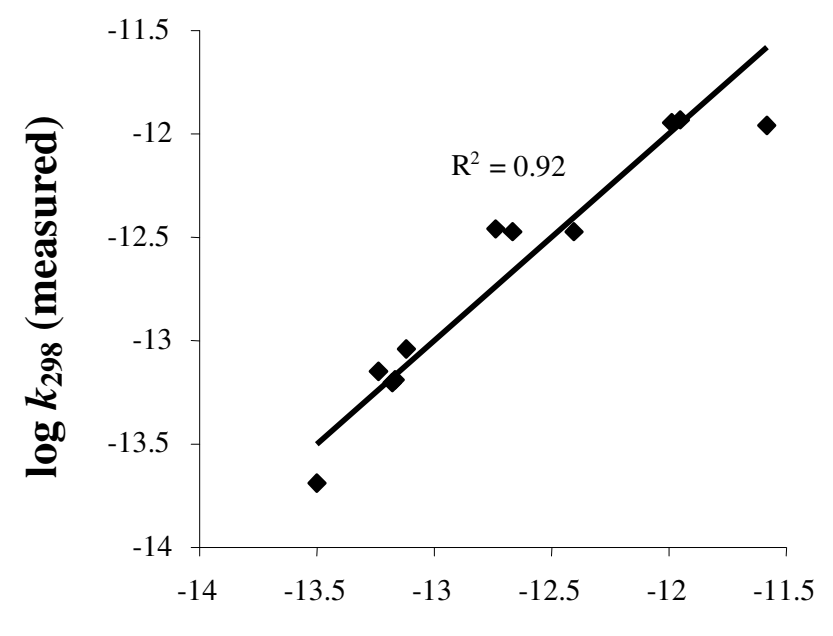

$\log k_{298}$ (modelled)

Fig. 4. $\log -\log$ plot of arene $+\mathrm{O}\left({ }^{3} P\right) k_{298}$ modelled using Eq. (2) against measured $k_{298}$.

the stability of the resonance structures of $m$-substituted radical transition states. The alkenylbenzene, $\beta$-dimethylstyrene is not included in these correlations because of its highly anomalous rate coefficient. The unusually slow rate coefficient of this compound was noted by the original experimental investigators (Chiorboli et al., 1983), who attributed the non-planar geometry of this compound's two methyl groups as a contributor to the steric hindrance of the molecule with respect to its otherwise reactive substituent unsaturated bond.

\section{$3.2 \mathrm{O}\left({ }^{3} P\right)$ dataset}

The second best correlation is observed for the $\mathrm{O}\left({ }^{3} P\right)$ dataset with $R^{2}=0.92$, furthermore the dataset possesses a similar range of reactivity to the $\mathrm{OH}$ dataset, although does not cover as wide a range in terms of structural diversity.

Figure 4 is a plot of $\log k_{298}$ against $\log k_{298}$ modelled using Eq. (2) where $a_{0}, b_{0}$ and $b_{1}$ are $13.15,-46.04$ and -1.62 respectively. Again, a good correlation is observed and it is expected that with supplementary data for $\Sigma x_{>0}^{\circ}$, a better correlation could be achieved by improving constraints on model parameters and spacing between $\Sigma x_{0-3}^{\circ}$.

\section{$3.3 \quad \mathrm{NO}_{3}$ dataset}

The $\mathrm{NO}_{3}$ dataset covers the largest range of reactivity, extending over seven orders of magnitude and is the second most extensive dataset in this study.

Figure 5 is a plot of Randić index against $\log k_{298}$ with respect to $\mathrm{NO}_{3}$. Unlike the other datasets, an inflection is observed in the data between alkylbenzenes and alkenylbenzenes. Treated as a single trendline, this phenomenon clearly contributes to scatter within the correlation of $\Sigma x_{0}^{\circ}$. Although data appear to segregate into $\Sigma x^{\circ}$ subgroups as 


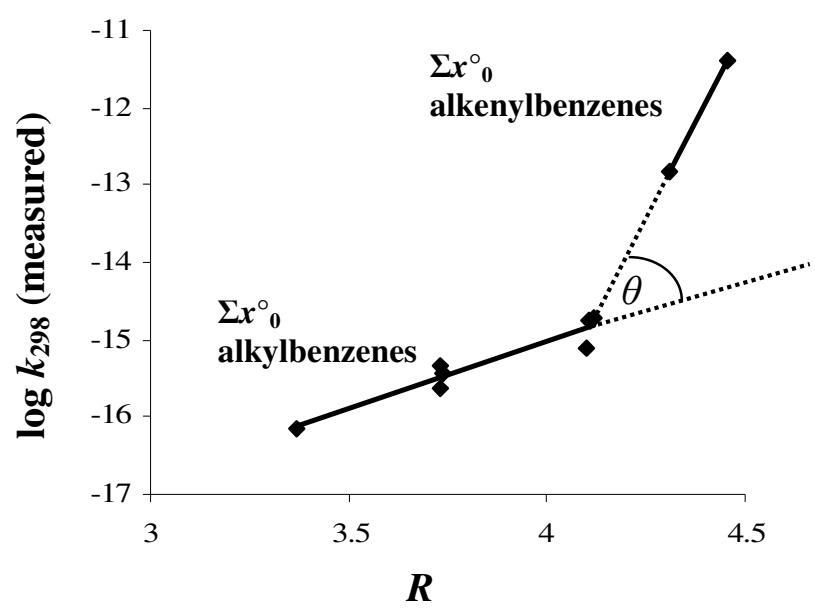

Fig. 5. log-log plot of Randić index against arene $+\mathrm{NO}_{3} k_{298}$ against measured $k_{298}$. Stippled lines represent forecasts of the $\Sigma x_{0}^{\circ}$ alkyl- and alkenylbenzene trendlines. The difference in gradient observed between these trendlines, denoted by $\theta$, is attributed to a difference in mechanism between the alkylbenzenes (where abstraction from alkyl substituents dominates) and alkenylbenzenes (where addition to alkenyl substituents dominates).

observed in the $\mathrm{OH}$ and $\mathrm{O}\left({ }^{3} \mathrm{P}\right)$ data, subgroups do not appear to exhibit the uniformity present in the $\mathrm{OH}$ data (this data is not presented in Fig. 5 for reasons of clarity) and further rate coefficient measurements from these subgroups would be expected to provide further insight into whether or not $\Sigma x^{\circ}$ subgroups are distributed in a manner analogous to those of $\mathrm{OH}$.

\section{$3.4 \quad \mathrm{H}$ dataset}

The $\mathrm{H}$ dataset is limited to six measurements. Despite this small sample size, correlation is excellent and appears to exhibit similar trends to those of $\mathrm{OH}$ and $\mathrm{O}\left({ }^{3} P\right)$. The $\Sigma x_{0}^{\circ}$ possesses a strong correlation coefficient of 0.99 , and the only known measurement of a $\Sigma x_{1}^{\circ}$ compound, ethylbenzene plots above the $\Sigma x_{0}^{\circ}$ trendline as expected. As with other species, kinetic measurements of $\Sigma x_{>0}^{\circ}$ would be expected to strengthen the relationships observed so far.

\subsection{Cl dataset}

Likewise limited to six measurements, the $\mathrm{Cl}$ correlation is strong, but may exhibit some curvature. It is anticipated that with further experimental measurements the $\Sigma x_{0}^{\circ}$ correlation could be strengthened, and it is expected that similar trends will emerge for $\Sigma x_{>0}^{\circ}$. However, given the rapidity of $\mathrm{Cl}-$ arene reactions, rate coefficients for many species will approach the collision limit and estimation methods will be unable to differentiate reactivity as it becomes pressure limited.

\section{Discussion}

The hydroxyl radical dataset is most comprehensive both in terms of number of rate coefficients and range of arene substitutions studied. As such, it is the most insightful with respect to the distribution of $\Sigma x^{\circ}$ subgroups and is used as a template for other radicals whose behaviour is assumed to be analogous (e.g. $\mathrm{O}\left({ }^{3} \mathrm{P}\right), \mathrm{H}$ and $\left.\mathrm{Cl}\right)$.

The hydroxyl dataset is likewise most useful for testing the effectiveness of the topological approach, since the established arene rate coefficient estimation method of Zetzsch (1982) and optimized further by Atkinson (1991), based on electrophilic substituent constants of Brown and Okamoto (1958) appears to have been developed solely for $\mathrm{OH}$-arene reactions. A direct comparison between the topological approach and Zetzsch's method is impossible, since the two techniques predict for a different range of aromatic compounds: the topological approach can describe alkenyl substitution whereas Zetzsch's method cannot, and Zetzsch's method considers oxygenated and nitrated substitution whereas the topological approach, at the time of writing has not been developed to do so. However, where overlap exists between the two methods (i.e. the alkylbenzenes), a comparison can be made, as is shown in Table 3. It is considered most intuitive to assess the predictive capabilities of the two methods by expressing a ratio relationship, $r$, between the estimated rate coefficient and the measured rate coefficient using Eq. (3).

$r=\frac{k_{\text {estimated }}}{k_{\text {measured }}}$

To ensure a direct comparison, where the measured rate coefficient exceeds the estimated rate coefficient, $r$ is inverted. As is evident from histograms of these data shown in Figs. 6a-b, the predictive capability of the topological approach is significantly better than Zetzsch's method, which exhibits a larger range of error and a more diffuse distribution across this range.

The range of arenes incorporated into the hydroxyl radical correlation surpasses Zetzsch's method in the sense that it includes alkenyl substituted species. This is a surprising result since the literature suggests that alkenyl substituted arenes react almost exclusively through radical addition to the substituted unsaturated bond (Calvert et al., 2002; personal communication, R. Atkinson, $2006^{1}$ ). A corollary of this hypothesis is that reactions involving alkenyl substituted arenes ought to react via a distinctly different mechanism to the remaining arenes, where radical addition to the aromatic ring, hydrogen abstraction from the substituent group(s) and hydrogen abstraction from the aromatic ring are possible mechanisms. The correlations observed in Figs. 2 and 3 appear to contradict this hypothesis, since alkenyl substituted arenes

\footnotetext{
${ }^{1}$ Atkinson, R.: University of California, Riverside, California, CA, personal communication, 2006.
} 
Table 3. Comparison between the predictive capabilities of the topological approach and the Zetzsch method using the ratio relationship, $r$ between rate coefficients of the respective estimation method and measured rate coefficients.

\begin{tabular}{lccccc}
\hline arene & $k_{\text {OHmeas. }}$ & $k_{\text {OHmod. }}$ & $r$ & $k_{\text {OHZetzsch }}$ & $r$ \\
\hline benzene & $1.19 \times 10^{-12}$ & $1.71 \times 10^{-12}$ & 1.44 & $2.30 \times 10^{-12}$ & 1.93 \\
toluene & $5.70 \times 10^{-12}$ & $4.61 \times 10^{-12}$ & 1.24 & $5.90 \times 10^{-12}$ & 1.04 \\
$p$-xylene & $1.30 \times 10^{-11}$ & $1.24 \times 10^{-11}$ & 1.05 & $7.10 \times 10^{-12}$ & 1.83 \\
$o$-xylene & $1.14 \times 10^{-11}$ & $1.27 \times 10^{-11}$ & 1.12 & $7.10 \times 10^{-12}$ & 1.61 \\
$m$-xylene & $2.09 \times 10^{-11}$ & $1.24 \times 10^{-11}$ & 1.68 & $1.50 \times 10^{-11}$ & 1.39 \\
mesitylene & $5.75 \times 10^{-11}$ & $3.34 \times 10^{-11}$ & 1.72 & $3.82 \times 10^{-11}$ & 1.51 \\
hemimellitene & $3.27 \times 10^{-11}$ & $3.51 \times 10^{-11}$ & 1.07 & $1.83 \times 10^{-11}$ & 1.79 \\
$\psi$-cumene & $3.25 \times 10^{-11}$ & $3.42 \times 10^{-11}$ & 1.05 & $1.83 \times 10^{-11}$ & 1.78 \\
ethylbenzene & $6.07 \times 10^{-12}$ & $5.26 \times 10^{-12}$ & 1.15 & $5.60 \times 10^{-12}$ & 1.08 \\
toluene $p$-ethyl & $1.36 \times 10^{-11}$ & $1.54 \times 10^{-11}$ & 1.13 & $7.10 \times 10^{-12}$ & 1.92 \\
toluene $o$-ethyl & $1.32 \times 10^{-11}$ & $1.58 \times 10^{-11}$ & 1.20 & $7.10 \times 10^{-12}$ & 1.86 \\
toluene $m$-ethyl & $2.24 \times 10^{-11}$ & $1.54 \times 10^{-11}$ & 1.46 & $1.43 \times 10^{-11}$ & 1.57 \\
$n$-propylbenzene & $5.71 \times 10^{-12}$ & $7.24 \times 10^{-12}$ & 1.27 & $7.50 \times 10^{-12}$ (a.) & 1.31 \\
cumene & $6.61 \times 10^{-12}$ & $5.09 \times 10^{-12}$ & 1.30 & $4.63 \times 10^{-12}$ & 1.25 \\
$p$-cymene & $1.51 \times 10^{-11}$ & $1.53 \times 10^{-11}$ & 1.01 & $1.21 \times 10^{-11}$ & 1.25 \\
tetralin & $3.44 \times 10^{-11}$ & $3.50 \times 10^{-11}$ & 1.01 & $1.14 \times 10^{-11}$ (b.) & 3.02 \\
benzene, tert-butyl & $4.85 \times 10^{-12}$ & $6.78 \times 10^{-12}$ & 1.40 & $4.30 \times 10^{-12}$ & 1.13 \\
\hline
\end{tabular}

a. Mode of calculation unclear from published methodology. Value taken from literature (Atkinson, 1987).

b. Mode of calculation unclear from published methodology. Value taken from literature (Kwok and Atkinson, 1995).
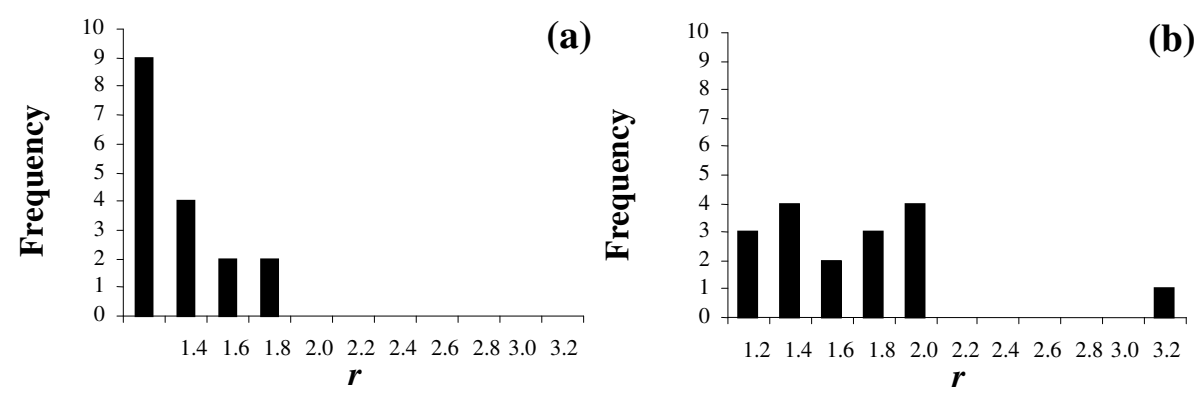

Fig. 6. (a) Histogram of the ratio relationship, $r$ between rate coefficients estimated using the topological approach and measured rate coefficients. (b) Histogram of the ratio relationship, $r$ between rate coefficients estimated using the Zetzsch method and measured rate coefficients.

fit seamlessly into the $\Sigma x_{0}^{\circ}$ trendline, a phenomenon that is observed in all datasets studied except for that of the nitrate radical. Short of comprehensive product analyses, this study can only offer a preliminary interpretation of this result, viz. that there are common mechanisms between alkenyl substituted arenes and other arenes. This hypothesis is supported by electron density calculations, which were executed using the MOPAC 5.0 (Stewart, 1983) package, implementing PM3 parameterizations. Such calculations indicate that aromatic rings possess comparable electron density to their alkenyl substituents, and ought therefore to possess similar reactivity.

From the strong correlations observed in the $\mathrm{O}\left({ }^{3} P\right), \mathrm{H}$ and $\mathrm{Cl}$ datasets, it appears that these radicals behave in an analogous way to the $\mathrm{OH}$ radical, as observed previously by Wayne et al. (1990). This is especially apparent in the $\mathrm{O}\left({ }^{3} P\right)$ correlation, where a similar range of reactivity is observed, and members of $\Sigma x_{0-3}^{\circ}$ plot in their respective fields on a scatter graph of $\log k_{298}$ vs. Randić index. However, each $\Sigma x_{>0}^{\circ}$ contains only one data point per subgroup, assuming there is scatter among these subgroups, the position of the respective trendlines of $\Sigma x_{1-3}^{\circ}$ is therefore rather conjectural at the time of writing, but could be constrained more accurately with further kinetic measurements of $\Sigma x_{>0}^{\circ}$ species. With this in mind, the method used for modelling the hydroxyl radical rate coefficients cannot be adapted easily to the other classes of compound with the present dataset because of uncertainties associated with deriving the model parameters in 
Eq. (2). However, the position of the $\Sigma x_{0}^{\circ}$ trendline is unlikely to change significantly, and it is recommended that, as a provisional method for $\Sigma x_{0}^{\circ}$ species, a simple linear regression fit between experimental rate coefficient data and the Randić index will produce estimated rate coefficients of satisfactory accuracy, given by the equation of the straight line, $y=m x+c$ of the linear regression. Where $y$ is $\log k_{298}, x$ is the Randic index of the compound in question, the gradient $m$ is $1.648,1.359$ and 1.052 for $\mathrm{O}\left({ }^{3} P\right), \mathrm{H}$ and $\mathrm{Cl}$ respectively and the $y$-intercept $c$ is $-18.628,-17.359$ and -13.836 for $\mathrm{O}\left({ }^{3} \mathrm{P}\right), \mathrm{H}$ and $\mathrm{Cl}$ respectively. For smaller datasets, $\mathrm{H}$ and $\mathrm{Cl}$, this method should be used with caution, since the small sample size precludes a confident analogy with the hydroxyl radical.

The nitrate radical dataset exhibits different and more complex behaviour than the $\mathrm{OH}, \mathrm{O}\left({ }^{3} P\right), \mathrm{H}$ and $\mathrm{Cl}$ radical datasets. This is to be expected, since the branching ratio between the reaction pathways of the nitrate radical with arenes are known to differ considerably from those of the hydroxyl radical and likely other radicals of similar behaviour - the major difference being the negligibility of the reaction of the $\mathrm{NO}_{3}$ radical with arene ring systems (Wayne et al., 1990). Evidence for this lack of interaction with the ring system is presented by the reversal of the trend of reactivity in $o-, m$ - and $p$-substituted alkylbenzenes observed in $\mathrm{OH}-$ arene reactions (Wayne et al., 1990), whereby $m$-substituted species are slowest, despite increased activation of reactive sites in the ring system. In contrast, it appears that interactions with the aromatic ring system are of primary importance in the reaction of arenes with the hydroxyl radical, since $m$-substitution enhances rates of reaction significantly. Since $\mathrm{NO}_{3}$ attack must therefore occur predominantly on arene substituent sites, the comparison between alkyl and alkenyl substituted arenes becomes analogous to a comparison between $\mathrm{NO}_{3}$-alkane and $\mathrm{NO}_{3}$-alkene reactions, which are kinetically and mechanistically dissimilar. It is therefore reassuring to note that the $\Sigma x_{0}^{\circ}$ trendline of the $\mathrm{NO}_{3}$ dataset (see Fig. 5) shows significant scatter, which results from the deviation of alkenyl substituted arenes, styrene and indene. It is also notable that the difference in gradient in the correlation of $\log k_{298}$ and Randić index between alkylbenzene and alkenylbenzene trendlines, denoted by $\theta$ in Fig. 5, is almost identical to that of alkanes and alkenes (not presented here) calculated using the same method ( 0.42 and 0.43 respectively).

The emergence of several trends in the $\mathrm{NO}_{3}$ dataset precludes accurate estimation of $\mathrm{NO}_{3}$-arene rate coefficients at this time, and it is expected that further experimental data especially from alkenyl substituted arenes and $\Sigma x_{>0}^{\circ}$ will provide greater insight into the interaction of nitrate radicals with arenes.

Despite the complex behaviour observed in the $\mathrm{NO}_{3}$ dataset, in general, correlations with radical-arene rate coefficients are excellent. Since the Randić-type index used only encodes the valency of carbon atoms with respect to other carbon atoms, their adjacency and a term for $\Sigma x^{\circ}$, other molecular properties are not incorporated in the index, and given the high level of correlation, appear to be of minor importance in comparison.

Despite the simplicity of the method used, this topological approach generates very strong relationships with the overall rate coefficients of arenes. Although an exact physical interpretation of what the Randić index measures remains subject to discussion (Estrada, 2002), the factors governing arene reactivity are simple enough that this index can describe them in adequate detail. The Randić index calculation requires few input parameters, and the result is a description of the connectivity of carbon atoms within the molecule. Other factors that might be expected to be of importance such as the geometry and 3-dimensional spatial configuration of a molecule appear to be minor in comparison and by considering the details that the Randić index omits, some qualitative insight may be gained regarding the relative importance of factors contributing towards arene reactivity.

\section{Atmospheric implications}

The impact of using rate coefficients estimated through our method versus the recommended values of Calvert et al. (2002) upon the output of an atmospheric model was assessed. The model has been described in detail before (Utembe et al., 2005) and uses the CRI mechanism described in detail by Jenkin et al. (2002). Initial comparisons were made using the full MCM mechanism and the CRI mechanism, where it emerged that the two mechanisms yielded the same results. The reduced mechanism was therefore adopted for the complete set of integrations, since it is more efficient to run. Briefly, the model was integrated for four days using a Gear type solver. Emissions of $\mathrm{NO}_{\mathrm{x}}, \mathrm{CO}, \mathrm{SO}_{2}, \mathrm{CH}_{4}$ and some 124 VOCs (detailed in previous papers) were incorporated into the model using the National Atmospheric Emissions Inventory (NAEI) (http://www.naei.co.uk). The box model was assumed to be static in space but was subjected to diurnally varying emissions, deposition (where this had a diurnally varying component), temperature and sunlight. A range of $\mathrm{NO}_{\mathrm{x}}$ conditions appropriate to the urban environment were required for this study, the $\mathrm{NO}_{\mathrm{x}}$ emissions were scaled by factors of $0.1,0.5,1.0,2.0$, and 3.0 and covered $\mathrm{NO}_{\mathrm{x}}$ concentrations from around $500 \mathrm{ppt}$ through to $20 \mathrm{ppb}$. Rate coefficients of arenes with respect to $\mathrm{OH}$ were obtained from measurement data as recommended by Calvert et al. (2002). The rate of change of each arene is dependent on its initial concentration, the level of emission, and the concentrations of atmospheric oxidants (mainly $\mathrm{NO}_{3}$ and $\mathrm{OH}$ ). The emissions of $\mathrm{NO}_{\mathrm{x}}, \mathrm{CO}, \mathrm{SO}_{2}$, and VOCs into the model are based on the UK totals for 2001 reported by the National Atmospheric Emissions Inventory. A range of $\mathrm{NO}_{\mathrm{x}}$ conditions appropriate to the urban environment were required for 


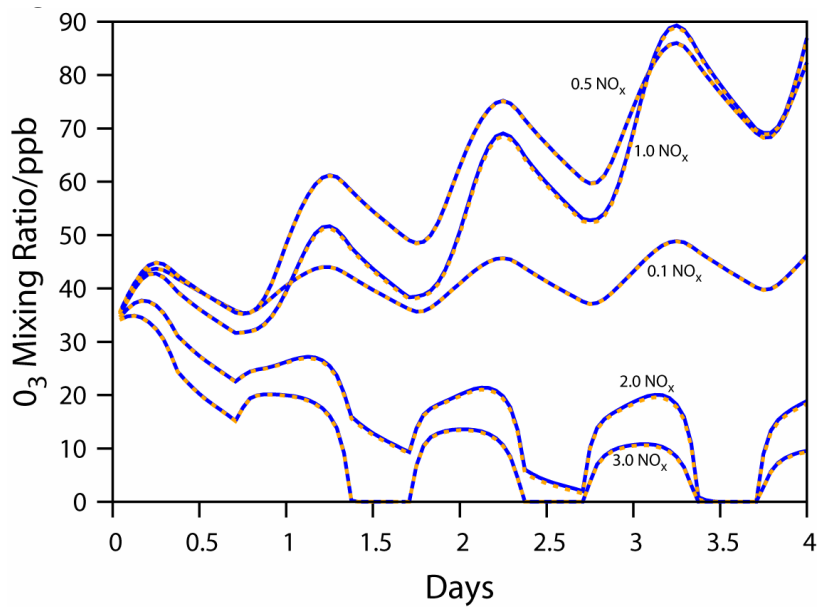

Fig. 7. Ozone mixing ratio modelled with different arene $+\mathrm{OH}$ rate coefficients. Rate coefficients taken from Calvert et al., 2002 and rate coefficients predicted by this work.

this study, the $\mathrm{NO}_{\mathrm{x}}$ emissions were scaled by factors of 0.1 , $0.5,1.0,2.0$, and 3.0.

The reduced mechanism was restricted to $\mathrm{C}_{\leq 8}$ arenes, therefore the list of arenes for which rate coefficients were altered are: benzene, toluene, $p$-xylene, $o$-xylene, $m$-xylene, mesitylene, hemimellitene, $\psi$-cumene, styrene, ethylbenzene, $p$-ethyltoluene, $o$-ethyltoluene, $m$-ethyltoluene, cumene, and $n$-propylbenzene. Figure 7 shows that over the whole range of $\mathrm{NO}_{\mathrm{x}}$ conditions, our rate coefficients estimates have a minor effect upon the modelled mixing ratios of ozone in comparison to using measurement data. Altering the rate coefficients between those predicted in this work and those recommended by Calvert et al. (2002) have a small impact on the relative rate of ozone production arising from the oxidation of these arenes (around 15-20\%) and have a negligible impact on the absolute rate of production $(<5 \%)$. The reason for the small impact on the absolute rate of production is that for those key arenes that contribute most to ozone formation (either because they are the highest emission or the fastest rate coefficient or both), the agreement between predicted and measured is very good (typically within 20\%). Furthermore, only minor effects were observed upon the concentrations of other major species (such as $\mathrm{NO}_{\mathrm{x}}$ and $\mathrm{HO}_{\mathrm{x}}$ ), especially under conditions of low $\mathrm{NO}_{\mathrm{x}}$. Differences in the concentrations of other important species e.g. formaldehyde (HCHO) and peroxyacetyl nitrate (PAN) mixing ratios only began to emerge at $\mathrm{NO}_{\mathrm{x}}$ emission factors greater than 1.0.

Further modelling studies were conducted to compare the estimates using the topological approach with those predicted using the Zetzsch method. As Zetzsch's method does not include alkenyl substituted arenes, the rate coefficient of styrene was not altered. The results suggest that rate coefficients predicted by the topological approach compare to measured values as well as, if not better than the values predicted

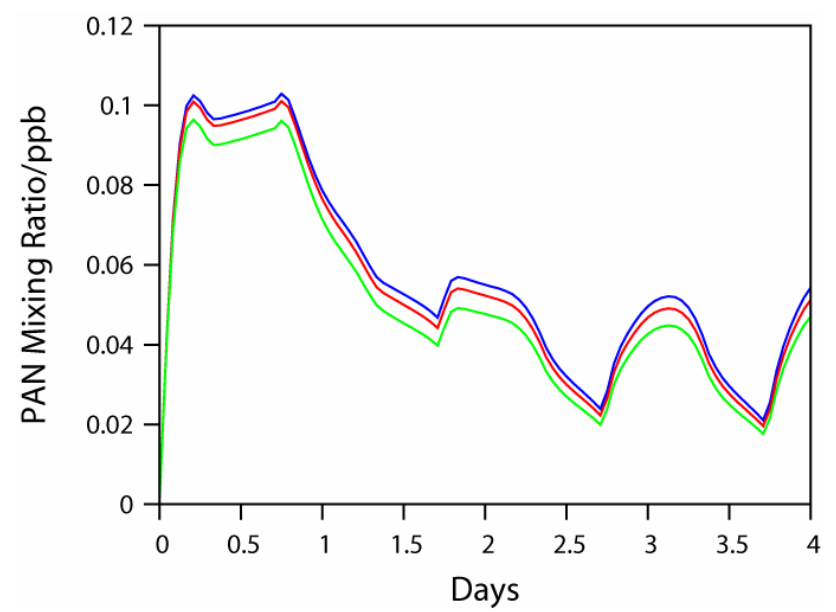

Fig. 8a. PAN mixing ratio modelled with different arene $+\mathrm{OH}$ rate coefficients. Rate coefficients taken from Calvert et al. (2002) rate coefficients predicted by this work and rate coefficients predicted by Zetzsch (1982).

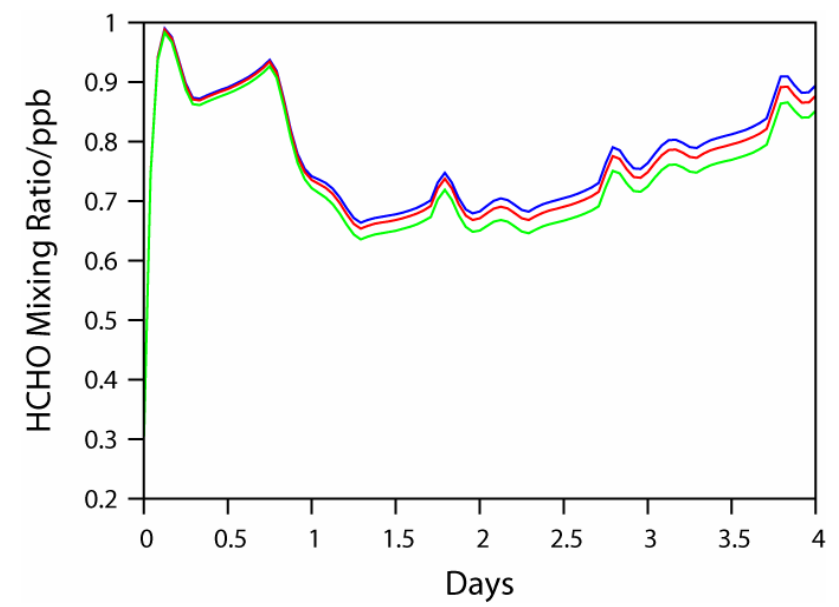

Fig. 8b. $\mathrm{HCHO}$ mixing ratio modelled with different arene $+\mathrm{OH}$ rate coefficients. Rate coefficients taken from Calvert et al. (2002) rate coefficients predicted by this work and rate coefficients predicted by Zetzsch (1982).

by Zetzsch. The differences between the Zetzsch method versus the topological approach become most apparent for [PAN] and [HCHO] under high $\mathrm{NO}_{\mathrm{x}}$ conditions (see Fig. 8).

As a result of these modelling studies, it is clear that rate coefficients perform well in a simplified version of the MCM, and it is suggested that the topological approach is most suitable for inclusion in the full MCM mechanism, where advantage could be made of the range of arene rate coefficients that can be predicted. It is further suggested that there are many species of arene for which kinetics with respect to atmospheric oxidants are not available that are present in vehicle exhaust emissions (e.g. AQIRP, 1995) and which therefore are of potential importance in urban environments, and it 
is probable that failure to account for these minor species will result in a greater error associated with model output than the error associated with the use of modelled versus measured rate coefficient data.

\section{Conclusions}

Strong relationships are observed in correlations between the Randić-type index of this study and $\log k_{298}$ for the reaction of arenes with $\mathrm{OH}, \mathrm{O}\left({ }^{3} \mathrm{P}\right), \mathrm{H}$ and $\mathrm{Cl}$ radicals. Correlation is particularly strong with the $\mathrm{OH}$ radical, whose dataset is superior in both number and range of compounds for which measurements are available. In the correlations of the remaining radical species considered (excluding $\mathrm{NO}_{3}$ ), behaviour is assumed to be analogous with the $\mathrm{OH}$ radical, and rate coefficients should therefore be predicted using the same method. Although, for these species, further rate coefficient measurements (preferably possessing as large a range in reactivity as possible) from $\Sigma x_{>0}^{\circ}$ are necessary in order to constrain the model parameters of Equation (II) accurately, facilitating accurate rate coefficient prediction for arenes belonging to $\Sigma x_{>0}^{\circ}$.

The present correlations with the $\mathrm{NO}_{3}$ radical appear to be complicated by mechanistic dissimilarity between alkyl and alkenyl substituted arenes, resulting in several relationships which are not sufficiently strong to enable accurate prediction of rate coefficients. Further measurements of both alkyl and alkenyl substituted arenes are required before this method can be used to predict $\mathrm{NO}_{3}$ rate coefficients accurately. However, the trends observed in the $\mathrm{NO}_{3}$ data suggest that the Randić-type index used in this study is able to identify mechanistically distinct behaviour.

With the exception of the nitrate reaction, correlations of alkenyl-substituted arenes accord with a general trend incorporating all arene species. This suggests that the reactions of alkenyl-substituted arenes and alkyl substituted arenes possess very similar mechanisms, contrary to the prevailing opinion in the literature, which suggests that reaction occurs almost exclusively on the alkenyl substituent (Calvert et al., 2002), an argument which appears to be founded upon the magnitude of alkenyl substituted species relative to their alkyl homologues and the two existing product studies of the $\mathrm{OH}+$ styrene reaction (Bignozzi et al., 1981; Tuazon et al., 1993). Here, the failure of $\mathrm{NO}_{3}$ to exhibit the same tendency as the other radicals provides a reference point by which mechanistically distinct behaviour can be recognized in these correlations, the relationships of the other radicals afford no such discrimination.

Modelling studies identified the topological approach as suitable for inclusion in complex atmospheric models such as the MCM, which at present uses measured rate coefficients for model input, and which may benefit from the range of species that can be predicted accurately through this approach.
In conclusion, this study finds the topological approach to be eminently suitable for the estimation of arene-radical gasphase rate coefficients, because it surpasses the methodology of Zetzsch (1982) and Atkinson (1991) both in terms of its diversity and its accuracy, since this method is able to predict every rate coefficient within a factor of two of the measured value (with the exception of the anomalously slow rate coefficient of $\beta$-dimethylstyrene). Furthermore, despite its simplicity, the topological approach represents an accurate description of arene reactivity, and as such an approximation of the important factors contributing towards this reactivity.

Edited by: A. Hofzumahaus

\section{References}

Anderson, R. S., Czuba, E., Ernst, D., Huang, L., Thompson, A. E., and Rudolph, J.: Method for measuring carbon kinetic isotope effects of gas-phase reactions of light hydrocarbons with the hydroxyl radical, J. Phys. Chem. A, 107, 6191-6199, 2003.

AQIRP: Effects of gasolineT50, T90 and sulfur on exhaust emissions of current and future technology vehicles, Auto/Oil Air Quality Improvement Research Program, Technical Bulletin No. 18, 1995.

Atkinson, R.: Kinetics and mechanisms of the gas-phase reactions of the hydroxyl radical with organic compounds under atmospheric conditions, Chem. Rev., 86, 69-201, 1986.

Atkinson, R.: A structure-activity relationship for the estimation of rate constants for the gas-phase reactions of $\mathrm{OH}$ radicals with organic compounds, Int. J. Chem. Kinet., 19, 799-828, 1987.

Atkinson, R.: Atmospheric lifetimes of dibenzo-para-dioxins and dibenzofurans, Sci. Total Environ., 104, 17-33, 1991

Atkinson, R. and Aschmann, S. M.: Kinetics of the reaction of acenaphthene and acenaphthylene and structurally-related aromatic compounds with $\mathrm{OH}$ and $\mathrm{NO}_{3}$ radicals, $\mathrm{N}_{2} \mathrm{O}_{5}$ and $\mathrm{O}_{3}$ at $296 \pm 2$ K, Int. J. Chem. Kinet., 20, 513-539, 1988.

Atkinson, R. and Aschmann, S. M.: Rate constants for the gasphase reactions of the $\mathrm{OH}$ radical with a series of aromatic hydrocarbons at 296 \pm 2 K, Int. J. Chem. Kinet., 21, 355-365, 1989.

Atkinson, R., Arey, J., and Aschmann, S. M.: Gas-phase reactions of azulene with $\mathrm{OH}$ and $\mathrm{NO}_{3}$ radicals and $\mathrm{O}_{3}$ at $298 \pm 2 \mathrm{~K}$, Int. J. Chem. Kinet., 24, 467-480, 1992.

Atkinson, R., Carter, W. P. L., Plum, C. N., Winer, A. M., and Pitts Jr., J. N.: Kinetics of the gas-phase reactions of $\mathrm{NO}_{3}$ radicals with a series of aromatics at $296 \pm 2$ K, Int. J. Chem. Kinet., 16, 887-898, 1984.

Baulch, D. L., Cobos, C. J., Cox, R. A., Esser, C., Frank, P., Just, T., Kerr, J. A., Pilling, M. J., Troe, J., Walker, R. W., and Warnatz, J.: Evaluated kinetic data for combustion modeling, J. Phys. Chem. Ref. Data, 21, 411-734, 1992.

Baulch, D. L., Cobos, C. J., Cox, R. A., Frank, P., Hayman, G., Just, T., Kerr, J. A., Murrells, T., Pilling, M. J., Troe, J., Walker, R. W., and Warnatz, J.: Evaluated kinetic data for combustion modelling, Supplement I, J. Phys. Chem. Ref. Data, 23, 8471033, 1994.

Bignozzi, C. A., Maldotti, A., Chiorboli, C., Bartocci, C., and Carassiti, V.: Kinetics and mechanism of reactions between aro- 
matic olefins and hydroxyl radicals, Int. J. Chem. Kinet., 13, 1235-1242, 1981.

Bohn, B.: Formation of peroxy radicals from $\mathrm{OH}-$ toluene adducts and $\mathrm{O}_{2}$, J. Phys. Chem. A, 105, 6092-6101, 2001.

Bolzacchini, E., Meinardi, S., Orlandi, M., Rindone, B., Hjorth, J., and Restelli, G.: Nighttime tropospheric chemistry: Kinetics and product studies in the reaction of 4-alkyl- and 4-alkoxytoluenes with $\mathrm{NO}_{3}$ in the gas-phase, Environ. Sci. Technol., 33, 461-468, 1999.

Brown, H. C. and Okamoto, Y.: Directive effects in aromatic substitution: electrophilic substituent constants, J. Am. Chem. Soc., 80, 4979-4987, 1958.

Buchta, C., Frerichs, H., Stucken, D. V., Tappe, M., and Wagner, H. G.: Kinetic and primary product studies of $\mathrm{O}\left({ }^{3} P\right)$ with styrene in the gas-phase, Ber. Bunsen. Phys. Chem., 97, 658-662, 1993.

Calvert, J. G., Atkinson, R., Becker, K. H., Kamens, R. M., Seinfeld, R. H., Wallington, T. J., and Yarwood, G.: The Mechanisms of Atmospheric Oxidation of Aromatic Hydrocarbons, Oxford University Press, New York, 2002.

Carletti, R. and Romano, D.: Assessing health risk from benzene pollution in an urban area, Environ. Monit. Assess., 80, 135-148, 2002.

Celik, A., Cavas, T., and Ergene-Gozukara, S.: Cytogenetic biomonitoring in petrol station attendants: micronucleus test in exfoliated buccal cells, Mutagenesis, 18, 417-421, 2003.

Chiorboli, C., Bignozzi, C. A., Maldotti, A., Giardini, P. F., Rossi, A., and Carassiti, V.: Rate constants for the gas-phase reactions of $\mathrm{OH}$ radicals with beta-dimethylstyrene and acetone - mechanism of beta-dimethylstyrene $\mathrm{NO}_{\mathrm{x}}$-air photo-oxidation, Int. J. Chem. Kinet., 15, 579-586, 1983.

Corchnoy, S. B. and Atkinson, R.: Kinetics of the gas-phase reactions of $\mathrm{OH}$ and $\mathrm{NO}_{3}$ with 2-carene, 1,8-cineole, $p$-cymene, and terpinolene, Environ. Sci. Technol., 24, 1497-1502, 1990.

Cvetanovic, R. J.: Evaluated chemical kinetic data for the reaction of atomic oxygen $\mathrm{O}\left({ }^{3} P\right)$ with unsaturated hydrocarbons, J. Phys. Chem. Ref. Data, 16, 261-326, 1987.

Derwent, R. G., Jenkin, M. E., and Saunders, S. M.: Photochemical ozone creation potentials for a large number of reactive hydrocarbons under European conditions, Atmos. Environ., 30, 181-199, 1996.

Estrada, E.: The structural interpretation of the Randić index, Internet J. Mol. Des., 1, 360-366, 2002.

Frerichs, H., Schliephake, V., Tappe, M., and Wagner, H. G.: Reactions of $o$-xylene, $m$-xylene and $p$-xylene with atomic oxygen $\left(\mathrm{O}^{3} P\right)$ in the gas-phase, Z. Phys. Chem. Neue Fol., 165, 9-22, 1989.

Frerichs, H., Stucken, D. V., Tappe, M., and Wagner, H. G.: Investigation of the reactions of benzonitrile, ethylbenzene and cumene with $\mathrm{O}\left({ }^{3} P\right)$ in the gas-phase, Z. Phys. Chem., 174, 1-9, 1991.

Gralewicz, S. and Wiaderna, D.: Behavioral effects following subacute inhalation exposure to $\mathrm{m}$-xylene or trimethylbenzene in the rat - A comparative study, Neurotoxicology, 22, 79-89, 2001.

Jenkin, M. E., Saunders, S. M., and Pilling, M. J.: The tropospheric degradation of volatile organic compounds: A protocol for mechanism development, Atmos. Environ., 31, 81-104, 1997.

Jenkin, M. E., Saunders, S. M., Derwent, R. G., and Pilling, M. J.: Development of a reduced speciated VOC degradation mechanism for use in ozone models, Atmos. Environ., 36, 4725-4734, 2002.
Kwok, E. S. C. and Atkinson, R.: Estimation of hydroxyl radical reaction rate constants for gas-phase organic compounds using a structure-activity relationship: An update, Atmos. Environ., 29, 1685-1695, 1995.

Kwok, E. S. C., Atkinson, R., and Arey, J.: Kinetics of the gas-phase reactions of indan, indene, fluorene, and 9,10dihydroanthracene with $\mathrm{OH}$ radicals, $\mathrm{NO}_{3}$ radicals, and $\mathrm{O}_{3}$, Int. J. Chem. Kinet., 29, 299-309, 1997.

Leppard, W. R., Benson, J. D., Burns, V. R., Gorse, R. A., Hochhauser, A. M., Knapper, J. C., Koehl, L. A., Rapp, L. A., and Reuter, R. M.: How Heavy Hydrocarbons in the Fuel Affect Exhaust Mass Emissions: Correlation of Fuel, Engine-out, and Tailpipe Speciation, SAE paper 932725, The Auto/Oil Air Quality Improvement Research Program, Society of Automotive Engineers, USA, 1993.

Leppard, W. R., Koehl, L. A., Benson, J. D., Burns, V. R., Hochhauser, A. M., Knapper, J. C., Painter, L. J., Rapp, L. A., Rippon, B. H., Reuter, R. M., and Rutherford, J. A.: Effects of Gasoline Properties ( $\mathrm{T}_{50}, \mathrm{~T}_{90}$, and sulfur) on Exhaust Hydrocarbon Emissions of Current and Future Vehicles: Speciation Analysis, SAE paper 952505, The Auto/Oil Air Quality Improvement Research Program, Society of Automotive Engineers, USA, 1995.

McGillen, M. R., Percival, C. J., Raventos-Duran, T., SanchezRayna, G., and Shallcross, D. E.: Can topological indices be used to predict gas-phase rate coefficients of importance to tropospheric chemistry? Free radical abstraction reactions of alkanes, Atmos. Environ., 40, 2488-2500, 2006a.

McGillen, M. R., Crosier, J. C., Percival, C. J., Sanchez-Rayna, G., and Shallcross, D. E.: Can topological indices be used to predict gas-phase rate coefficients of importance to tropospheric chemistry? Reactions of alkenes with $\mathrm{OH}, \mathrm{NO}_{3}$ and $\mathrm{O}_{3}$, Chemosphere, 65, 2035-2044, 2006b.

Mikkelsen, S.: Epidemiological update on solvent neurotoxicity, Environ. Res., 73, 101-112, 1997.

Odum, J. R., Jungkamp, T. P. W., Griffin, R. J., Forstner, H. J. L., Flagan, R. C., and Seinfeld, J. H.: Aromatics, reformulated gasoline, and atmospheric organic aerosol formation, Environ. Sci. Technol., 31, 1890-1897, 1997.

Ohta, T. and Ohyama, T.: A set of rate constants for the reactions of $\mathrm{OH}$ radicals with aromatic hydrocarbons, B. Chem. Soc. Jpn., 58, 3029-3030, 1985.

Pellack-Walker, P. and Blumer, J. L.: DNA damage in L5178YS cells following exposure to benzene metabolites, Mol. Pharmicol., 30, 42-47, 1986.

Randić, M.: Characterization of molecular branching, J. Am. Chem. Soc., 97, 6609-6615, 1975.

Shi, J. C. and Bernhard, M. J.: Kinetic studies of Cl-atom reactions with selected aromatic compounds using the photochemical reactor-FTIR spectroscopy technique, Int. J. Chem. Kinet., 29, 349-358, 1997.

Triebert, J., Engelmann, L., Olzmann, M., and Scherzer, K.: On the kinetics of reactions of hydrogen atoms with aromatic hydrocarbons, Z. Phys. Chem., 205, 33-40, 1998.

Tuazon, E. C., Arey, J., Atkinson, R., and Aschmann, S. M.: Gasphase reactions of 2-vinylpyridine and styrene with $\mathrm{OH}$ and $\mathrm{NO}_{3}$ radicals and $\mathrm{O}_{3}$, Environ. Sci. Technol., 27, 1832-1841, 1993.

Utembe, S. R., Jenkin, M. E., Derwent, R. G., Lewis, A. C., Hopkins, J. R., and Hamilton, J. F.: Modelling the ambient dis- 
tribution of organic compounds during the August 2003 ozone episode in the southern UK, Faraday Discuss., 130, 311-326, 2005.

Wayne, R. P., Barnes, I., Biggs, P., Burrows, J. P., Canosa-Mas, C. E., Hjorth, J., Le Bras, G., Moortgat, G. K., Perner, D., Poulet, G., Restelli, G., and Sidebottom, H.: The nitrate radical: physics, chemistry, and the atmosphere, Air Pollution Research Report 31, Commission of the European Communities, Belgium, 1990.
Zetzsch, C.: Predicting the rate of $\mathrm{OH}$-addition to aromatics using $\sigma^{+}$-electrophilic substituent constants for mono- and polysubstituted benzene, Proc. XVth Informal Conference on Photochemistry, Stanford, 29-32, 1982. 